\title{
Performance comparison of different control strategies for the regulation of DC-DC negative output super-lift luo-converter
}

\author{
Hassan Jassim Motlak, Ahmed S. Rahi \\ Department of Electrical Engineering, University of Babylon, College of Engineering, Iraq
}

\begin{tabular}{l}
\hline \hline Article Info \\
\hline Article history: \\
Received Feb 6, 2020 \\
Revised May 3, 2020 \\
Accepted May 15, 2020 \\
\hline
\end{tabular}

\section{Keywords:}

Current mode control

DC-DC converter

Nonlinear controller

Sliding-mode control

Voltage mode control

\begin{abstract}
In last years, DC-DC converters solve the most issues in the industrial application in the area of power electronics, especially renewable energy, military applications and affiliated engineering developments. They are used to convert the DC input that unregulated to regulated output perhaps larger or smaller than input according to the type of converters. This paper presents three primary control method used for negative output Super lift Luo DC-DC converter. These methods include a voltage mode control (VMC), current mode control (CMC), and Sliding mode control (SMC). The goal of this article is to study and selected an appropriate and superior control scheme for negative DC-DC converters. The simulation results show the effectiveness of Sliding mode control for enhancing the performance of the negative DC-DC converter. Also, this method can keep the output voltage constant under load conditions. Simulation results obtained by the MATLAB/Simulink environment.
\end{abstract}

Copyright $\odot 2020$ Institute of Advanced Engineering and Science. All rights reserved.

\section{Corresponding Author:}

\author{
Ahmed S. Rahi, \\ Department of Electrical Engineering, \\ University of Babylon, \\ College of Engineering, Babylon, Iraq \\ Email: ahmed.swadi79@gmail.com
}

\section{INTRODUCTION}

Nowadays, the increasing demand for energy, the search for new and cheap energy sources has become the best solution. Natural sources have become the best in generating electricity because it has many advantages such as low pollution, cheap price, and easy access, it is available everywhere. Here we talk about the sources of the sun, wind, sea waves and other natural sources $[1,2]$. But the sun is the main source and available everywhere. In this case, the generation of electricity from solar panels is a DC voltage. Since sunlight is not available at night. Therefore, the need to charge the batteries with power becomes the best solution. Here lies the need and demand to switch from DC-DC conversion to change voltage or current [2]. As well as other devices within them many stages that require conversion to varying voltages so needs to improve dc-dc conversion [3]. The DC-DC converters using many methods to control the switching in order to keep the outputs of these circuits are constant under load conditions. Where it requires stability in voltage, Low ripple, and high efficiency. As well as raising and lowering the voltage according to the load conditions. Effective role of the control department in that. There many control circuits. Each one has advantages, disadvantages and special use. In literature, many researchers have proposed a control method for DC-DC converters in order to keep output voltage is stable. In [3,4] presented three main methods are including a Voltage mode control, Current mode control and Sliding mode control. In [5], the design of SMC with negative output super-lift Luo converter (NOSLC) has been presented. The performance of SMC in this article is robustness in terms of sudden change in input voltage and output load. The brain emotional learning with indirect voltage-mode control for boost converter is presented in [6] to achieve constant output voltage. The three-method control which includes voltage mode control, current-mode control and SMC with buck 
converter have been proposed by [7] in order to compare between them in terms of response and output ripple. In [8] the dual-loop current controller-based and optimized for current stabling of a Zeta converter is proposed and analyzed in continuous current mode. Also, in [9-12] design a unified approach which consist PWM based sliding voltage controllers to suitable with all types of DC-DC converters. While in [13] the overviews of virous control scheme have been presented in this paper in order to select the apportuinte method for DC-DC converters. In [14], this article introduces a comprehensive review about DC-DC converters in two types isolated and nonisolated for renewable energy application. It can be seen that the super lou converter and ultera super lift converter have high gain ratio thus these converters are very benficial for the application that need high step up output voltage. In [15], the new data driven for desighn PI controller has been discussed and analysis in this article for tracking of angular velocity trajectory. The siliding mode control is presented in [16] for regulated the output voltage of buck converter. In [17], the optimization tuning of PI parameters using a hybrid partical swarm optimization and gravitational search algorithm for SMC have been discussed and analysis. The bidirectional DC-DC converter control method has been presented in [18]. While in [19], the novel control of boost converter in continuous condiction mode plane is presented and analysis. The reviews of designed of different dc dc converters for battery charge of electrical vehicle application have been discussed and analysis in [20-22]. In this paper the comparison between three method control (voltage mode control, current-mode control and sliding mode control) with NOSLC to choose a better method in terms of a low ripple, fast response to a sudden change in load and efficiency.

\section{RESEARCH METHOD}

\subsection{Mathematical modeling of NOSLLC}

It consists of a control switch (MOSFET), two uncontrolled switch diodes (D), inductance (L), two capacitors (C) and load resistance as shown in Figure 1. This converter can be providing high voltage gain in opposite sign of input voltage, and the output voltage increase arithmetic progression [23]. The output voltage equation can express as.

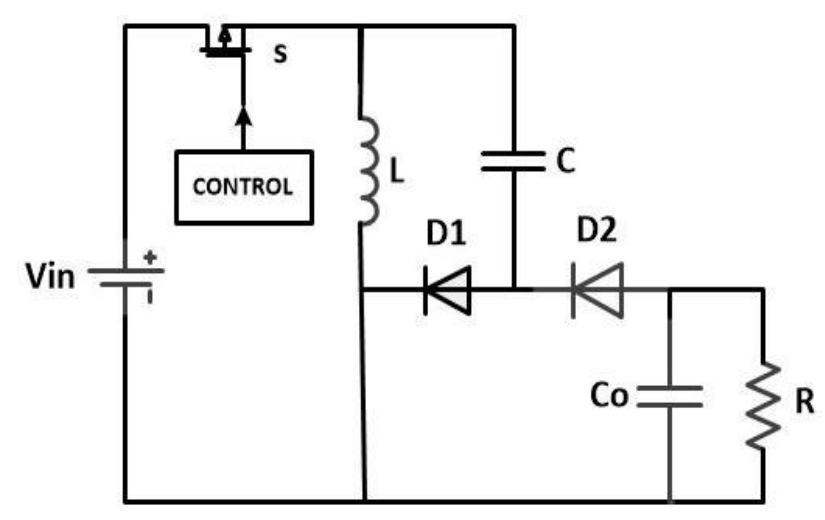

Figure 1. Negative output super-lift Luo converter (NOSLLC)

Switch ON

$$
\begin{aligned}
& \mathbf{v}_{\text {in }}=\mathrm{v}_{\mathrm{L}}=\mathrm{v}_{\mathrm{c}} \\
& \mathrm{v}_{\text {in }}=\mathrm{v}_{\mathrm{L}}
\end{aligned}
$$

Switch OFF

$$
\begin{aligned}
& \mathrm{v}_{\mathrm{o}}+\mathrm{v}_{\mathrm{c}}-\mathrm{v}_{\mathrm{L}}=0 \\
& \mathrm{v}_{\text {in }}=\mathrm{v}_{\mathrm{c} 1} \\
& \mathrm{v}_{\mathrm{L}}=\mathrm{v}_{\mathrm{o}}+\mathrm{v}_{\text {in }}
\end{aligned}
$$




$$
\begin{aligned}
& D v_{\text {in }}+\left(v_{o}+v_{\text {in }}\right)(1-D)=0 \\
& v_{o}=-\frac{v_{\text {in }}}{1-\mathrm{D}}
\end{aligned}
$$

The design of capacitors and inductor according to the equations:

$$
\begin{aligned}
& \Delta_{V O}=\frac{(1-\mathrm{d})}{f c} \frac{V_{O}}{R} \\
& \Delta_{i L}=\frac{\left(V_{o}-V_{i n}\right)}{L} D t \\
& \Delta_{v c}=\frac{\left(V_{c}\right)}{R C} D t
\end{aligned}
$$

\subsection{Voltage mode control (VMC)}

The output voltage feedback is compared with the reference (equal to design output voltage) then the comparison result will be amplified by error amplifier, the pulse-width modulated waveform is generated by comparing the error voltage with a saw-tooth ramp signal [3, 24] The coefficient of the voltage mode control NOSL converter in Figure 2 can thus be obtained as follow [25, 26].

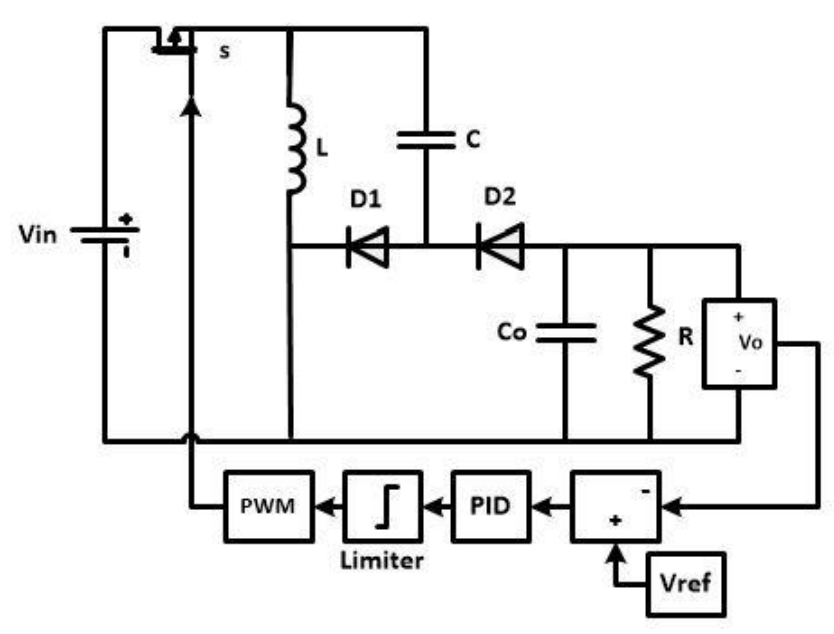

Figure 2. Voltage mode control (VMC)

\subsection{Indirect voltage mode control (IVMC)}

Indirect voltage mode control is the second method that come from combination the VMC in Figure 2 and current mode control (CMC) in Figure 3, the IVMC is shown in Figure 4. That uses the inductor current as feedback for both circuits [6]. Initially, the principle of CMC is the inductor current will enter the comparator circuit, and here it will be compared to the reference current $\left(\mathrm{I}_{\text {ref. }}\right)$. After the comparison, the result is a difference value, which is the signal that represents the error rate. Signal will pass through the controller (PI) to amplifying the signal and increasing the response speed. The output of the controller (PI) is a voltage because it is an integral result and then the signal enters into a limiter circuit. To ensure the signal limits. After that, the signal enters the circuit of (PWM). In the end, the output is a signal of control represented by duty cycle and frequency of the switch control signal that is dominated at any Sudden change in load, then it enters the switch, the result is an increase or decrease in the output voltage to maintain output is stable $[3,27,6]$.

The difference in circuit Figure 4 is the reference current (Iref). Where it was not a fixed number as before, but rather it comes from a more accurate process represented by entering the output voltage on the subtraction process with a reference voltage and the result is an error value that passes through the PI to get the signal amplification and converted to current and then to a limiter to replace the current reference (Iref) in Figure 3. This method is more efficient and effective because of its combination of advantages (VMC) and (CMC) [4, 6, 24]. 


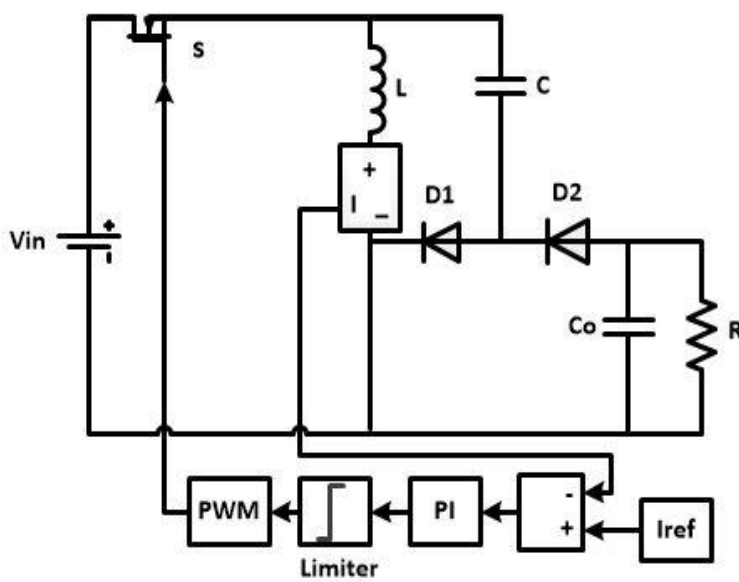

Figure 3. Current mode control (CMC)

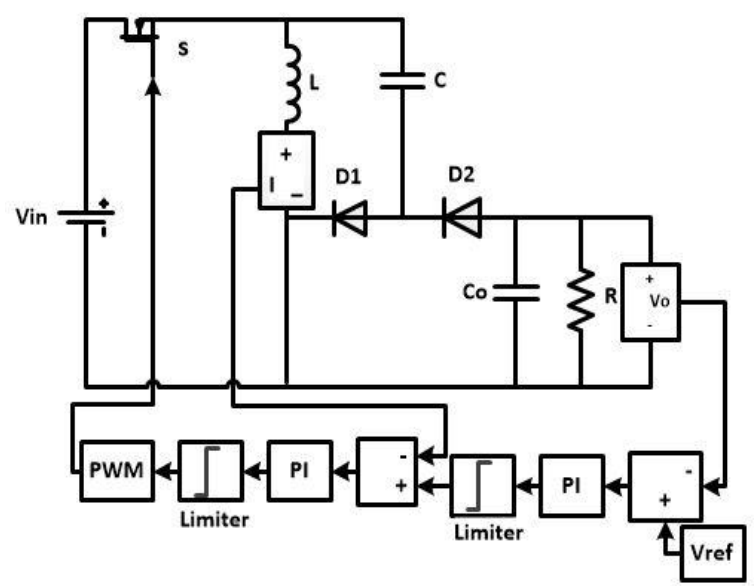

Figure 4. Indirect voltage mode control (IVMC)

\subsection{Sliding mode control (SMC)}

Sliding mode control (SMC) is the third type of control circuit DC-DC converter. Which is controlled by voltage and current. In the beginning, the output voltage signal and the input voltage signal enter on the subtraction circuit a result will be an error value and then magnified by $(\beta)[3,5]$. Also, the output voltage signal again magnified by $(\beta)$ and then enters into the subtraction circuit with a reference voltage (design value) that produces the error, which is an error rate that is enlarged by constant (KP). An inductor current signal is also enlarged by constant $\left(\mathrm{KP}_{2}\right)$. Here all three outputs enter the addition process. The result of the addition process is subtraction with the error value multiplied by $(\beta)$ terminal so a final error signal that produces. Then the output enters into a limiter circuit to ensure its comparison perfectly, finally, the signal passes through a AND gate that process it with a square wave for the purpose of obtaining a wave whose frequency that controls on a switch to control the switching of the converter. Therefore, this control method is fast to respond to the changes that occur in the input voltage, the output voltage and the current of the inductor and more efficient, less ripple and more accurate control in comparison with the previous methods according to the simulation results $[9,25,28]$. It is considered the best, most effective and practical method because in the Figure 5, the control schematic has three subtractions and one addition, so:

a) The result of the addition is too big and the result is not real error.

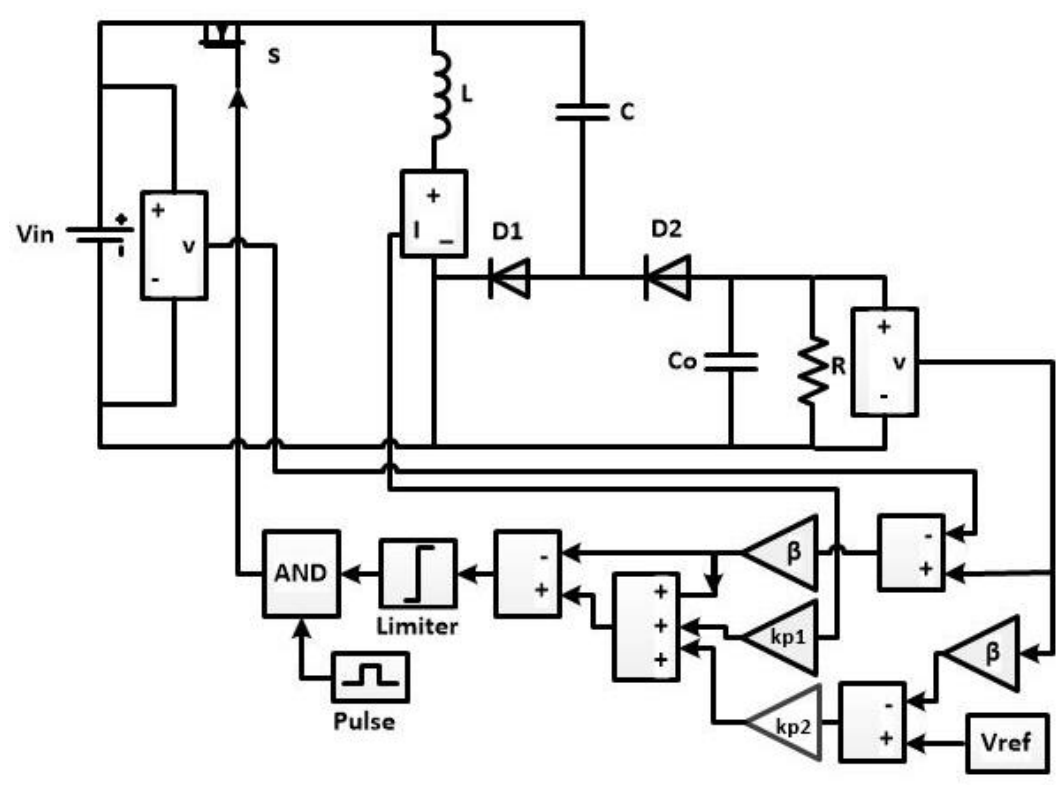

Figure 5. Sliding mode control with (NOSLC) 
b) The reason for making a second subtraction stage after the summation is product with one party and not the other. It is voltage with voltage. It is also the best among other parties because it includes the output of the input and output voltage, and this is not found in other parties. The details of design and mathematical model of this technique is presented in [9]. So, the summarize equations can be written as:

$$
\begin{aligned}
& \beta=\frac{v_{r e f}}{v o} \\
& k_{p}=\beta L\left(\frac{v_{r e f}}{v o}\right) \\
& \frac{\alpha 1}{\alpha 2}=\left(\frac{10}{T_{S}}\right) \text { and } \frac{\alpha 3}{\alpha 2}=\left(\frac{25}{\xi^{2} T_{S}^{2}}\right) \text { where } T_{S}=5 \tau \\
& \xi=\sqrt{\frac{\left[\ln \frac{M_{P}}{\pi^{2}+\left[\ln \frac{M_{P}}{100}\right]^{2}}\right.}{k_{P 1}}=\beta L\left(\left(\frac{\alpha 1}{\alpha 2}\right)-\left(\frac{1}{R_{L} C}\right)\right)} \\
& k_{P 2}=L C\left(\frac{\alpha 3}{\alpha 2}\right)
\end{aligned}
$$

\section{RESULTS AND DISCUSSION}

Three methods of control are applied to a negative super lift converter in order to comparative between them in terms of tracking response and regulated output voltage under changeable condition (variable reference voltage and variable load resistance). The test parameters of negative converter are designing according to equations (8-10). So, these parameters are scheduling in Table 1 . The mathematical model and design of NOSLC are calculated in section 2. As well as, the dynamic performance is performed and evaluated in MATLAB/Simulink.

Table 1. Specification parameters of noslc and control

\begin{tabular}{llll}
\hline No. & Parameter & Symbol & Value \\
\hline 1 & Input Voltage & Vin & $12 \mathrm{~V}$ \\
2 & Output Voltage & Vo & $-36 \mathrm{~V}$ \\
3 & Inductor & L & $100 \mu \mathrm{H}$ \\
4 & Capacitor & $\mathrm{C} 1$ & $30 \mu \mathrm{F}$ \\
5 & Output Capacitor & $\mathrm{Co}$ & $470 \mu \mathrm{F}$ \\
6 & Load resistance & $\mathrm{R}$ & $50 \Omega$ \\
7 & Duty cycle & $\mathrm{D}$ & 0.66 \\
8 & Switching frequency & fs & $20 \mathrm{kH}$ \\
9 & Coefficient of sliding mode & Kp1, Kp2 & $0.1 ; 1.2$ \\
10 & feedback divider ratio & $\beta$ & $1 / 6$ \\
\hline
\end{tabular}

Figure 6 shows the tracking reference of output voltage for VMC, IVMC and SMC methods. The reference value is changed during period $1.5 \mathrm{sec}$ and note that the target value is investigated at very small settling time. It has been seen that the result of SMC method has fast response and tracking with desired voltage, but, the VMC has ripple with low value of load resistance $(\mathrm{R}=35 \mathrm{ohm})$ as compare with IVMC and SMC.

Figure 7 shows the response of three methods for various load resistance (35, 50, and $100 \mathrm{ohm}$ respectively). It notes that the SMC has better behavior performance from VMC and IVMC in terms of lower ripple and fast-tracking with desired voltage. Finally, Figure 8 shows the comparison of tracking reference with target value between three control method in order to distinguish the priority method in terms of achieving the value of the target and settling time. It has been seen that the SMC is implemented correctly operation in any changing or working conditions for NOSLC.

In order to find the superiority of proposed control methods especially SMC, the SMC is compared with [5] and [25] in terms of response for changing reference voltage and load, ripple, tracking, rise time, settling time and overshoot. It notes that the SMC has better performance as compared with above references in terms of low ripple, fast tracking with reference and low overshoot as shown in Table 2. 


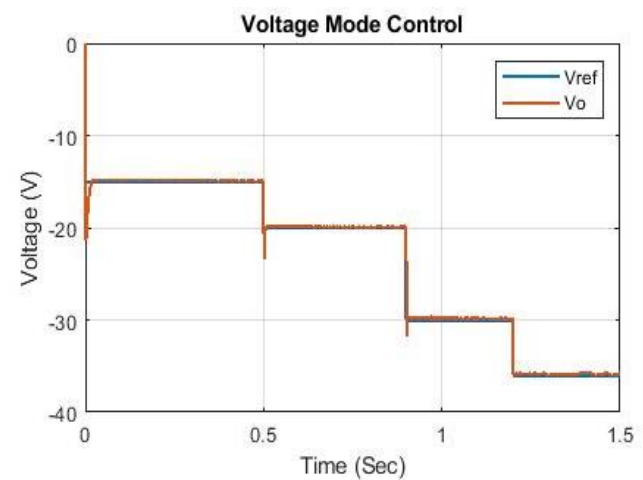

(a)

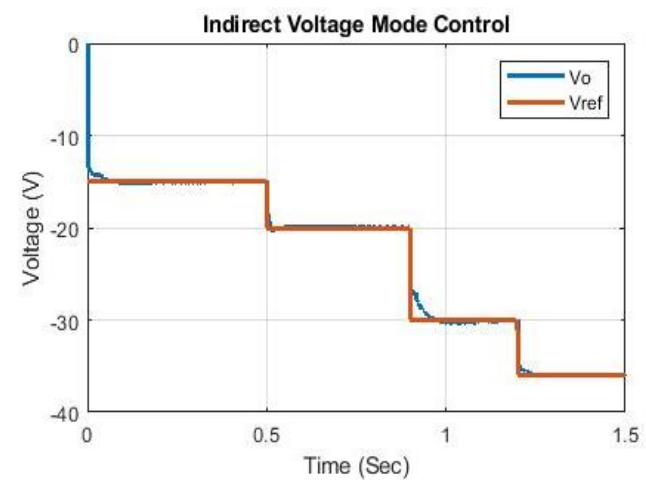

(b)

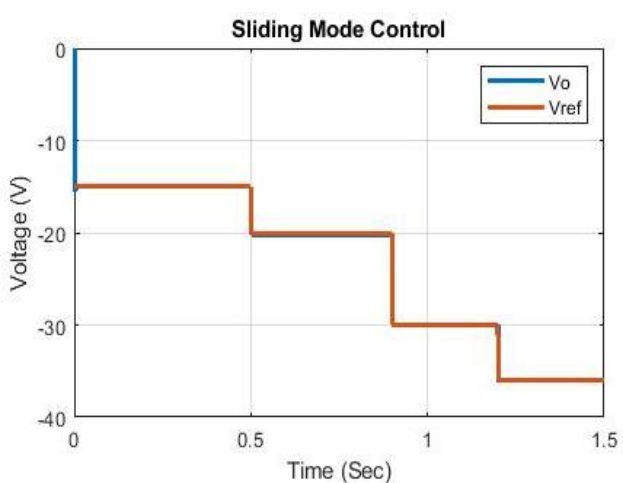

(c)

Figure 6. Reference tracking of NOSLC with (a) VMC, (b) IVMC, and (c) SMC

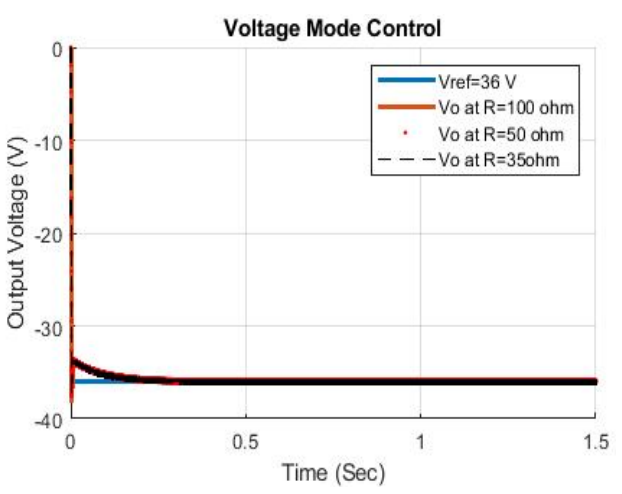

(a)

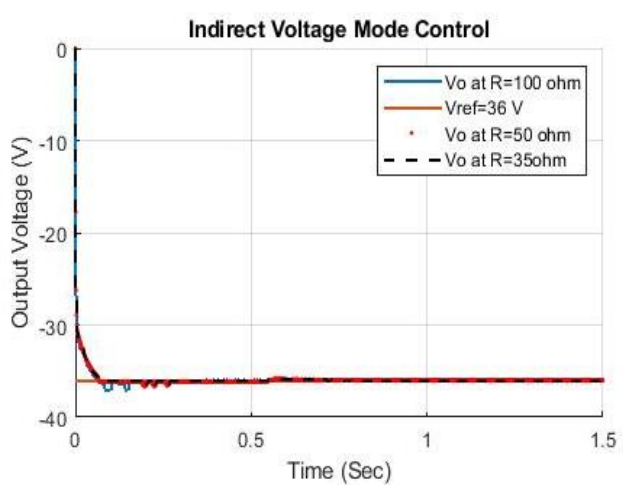

(b)

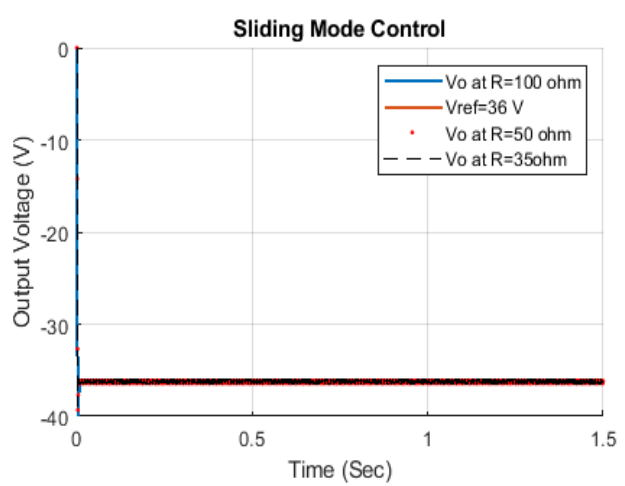

(c)

Figure 7. Response of NOSLC for varying load resistance with (a) SMC, (b) IVMC, and (c) SMC 


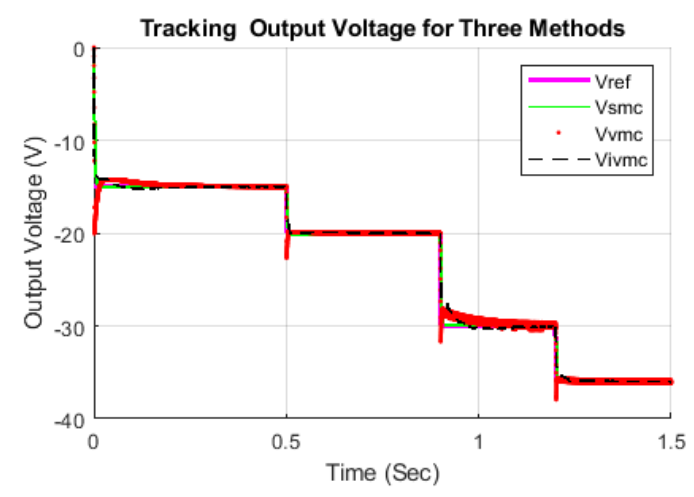

Figure 8. Comparison of reference tracking of NOSLC with three methods

Table 2. Compare the simulation results with other references

\begin{tabular}{lllll}
\hline No. & Performance Index & Simulation Results & Reference [5] & Reference [25] \\
\hline 1 & Speed Response & $\begin{array}{l}\text { High Response for } \\
\text { Changing Load }\end{array}$ & $\begin{array}{l}\text { Low Response for } \\
\text { Changing Load }\end{array}$ & $\begin{array}{l}\text { High Response for } \\
\text { Changing Load }\end{array}$ \\
2 & Settling Time & Very Small Settling Time & Small Settling Time & Very Small Settling Time \\
3 & Rise Time & Very Small & Small & Very Small \\
4 & Overshoot & Low (1.5V for SMC) & High (3.5 V) & High (3V) \\
6 & Ripple & Low & High & High \\
7 & Tracking & Fast & Very Less Than & Less Than \\
\hline
\end{tabular}

\section{CONCLUSION}

Three control methods are applied in this paper to achieve a high response and low ripple for output negative super lift Luo converter. All of these methods were implemented on a negative converter via the MATLAB program. The simulation results show the SMC method has a better performance an fast-tracking of reference value as well as its robustness against disturbances. It can achieve a perfect control effect because of the dependence of the three input feedback coefficients.

\section{REFERENCES}

[1] F. M. Shahir, E. Babaei, And M. Farsadi, "Voltage-Lift Technique Based Nonisolated Boost Dc-Dc Converter: Analysis and Design," In IEEE Transactions on Power Electronics, vol. 33, no. 7, pp. 5917-5926, Jul. 2018.

[2] B. Axelrod, Y. Berkovich and A. Ioinovici, "Switched-Capacitor/Switched-Inductor Structures for Getting Transformerless Hybrid Dc-Dc Pwm Converters," In IEEE Transactions on Circuits and Systems I: Regular Papers, vol. 55, no. 2, pp. 687-696, Mar. 2008.

[3] F. Wang, J. Xu and B. Wang, "Comparison Study of Switching Dc-Dc Converter Control Techniques," 2006 International Conference on Communications, Circuits, And Systems, Guilin, pp. 2713-2717, 2006.

[4] K. Wan, J. Liao, And M. Ferdowsi, "Control Methods in DC-DC Power Conversion - A Comparative Study," 2007 IEEE Power Electronics Specialists Conference, Orlando, Fl, pp. 921-926, 2007.

[5] K. Ramash Kumar and S. Jeevananthan, "Design of Sliding Mode Control for Negative Output Elementary Super Lift Luo Converter Operated in Continuous Conduction Mode," 2010 International Conference on Communication Control and Computing Technologies, Ramanathapuram, pp. 138-148, 2010.

[6] S. Khorashadizadeh and M. Mahdian, "Voltage Tracking Control of Dc-Dc Boost Converter Using Brain Emotional Learning," $20164^{\text {th }}$ International Conference on Control, Instrumentation, and Automation (Iccia), Qazvin, pp. 268-272, 2016.

[7] Himanshu and R. Khanna, "Various Control Methods for Dc-Dc Buck Converter," 2012 IEEE Fifth Power India Conference, Murthal, pp. 1-4, 2012.

[8] Goudarzian, A., Khosravi, A. and Abjadi, N.R., "Input-Output Current Regulation of Zeta Converter Using an Optimized Dual-Loop Current Controller," Electrical Engineering, vol. 102, no. 1, pp. 1-13, 2019.

[9] Siew-Chong Tan, Y. M. Lai and C. K. Tse, "A Unified Approach to the Design of Pwm-Based Sliding-Mode Voltage Controllers for Basic Dc-Dc Converters in Continuous Conduction Mode," In IEEE Transactions on Circuits and Systems I: Regular Papers, vol. 53, no. 8, pp. 1816-1827, Aug. 2006.

[10] K. R. Kumar and S. Jeevananthan, "Modelling and Implementation of Fixed Switching Frequency Sliding Mode Controller for Negative Output Elementary Super Lift Luo-Converter," In IET Power Electronics, vol. 5, no. 8, pp. 1593-1604, Sep. 2012.

[11] El Aroudi, A., Martínez-Treviño, B.A., Vidal-Idiarte, E., Cid-Pastor, A., "Fixed Switching Frequency Digital Sliding-Mode Control of DC-DC Power Supplies Loaded by Constant Power Loads with Inrush Current Limitation Capability," Energies, vol. 12, pp. 1-27, 2019. 
[12] L. Shen, D. D. Lu and C. Li, "Adaptive Sliding Mode Control Method for Dc-Dc Converters," In IET Power Electronics, vol. 8, no. 9, pp. 1723-1732, 2015.

[13] N. Bajoria, P. Sahu, R. K. Nema and S. Nema, "Overview of different control schemes used for controlling of DC-DC converters," 2016 International Conference on Electrical Power and Energy Systems (ICEPES), Bhopal, pp. 75-82, 2016.

[14] Raghavendra, K.V.G., et al., "A Comprehensive Review of DC-DC Converter Topologies and Modulation Strategies with Recent Advances in Solar Photovoltaic Systems," Electronics, vol. 9, no. 1, pp. 1-41, 2020.

[15] M. A. Ahmad and R. M. T. R. Ismail, "A data-driven sigmoid-based PI controller for buck-converter powered DC motor," 2017 IEEE Symposium on Computer Applications \& Industrial Electronics (ISCAIE), Langkawi, Malaysia, pp. 81-86, 2017.

[16] Mustafa A. Fadel Al-Qaisi, Mohanad A. Shehab, Ammar Al-Gizi, Mohammed Al-Saadi, "High performance DC/DC buck converter using sliding mode controller," International Journal of Power Electronics and Drive System (IJPEDS), vol. 10, no. 4, pp. 1806-1814, Dec. 2019.

[17] M. Thirumeni and D. Thangavelusamy, "Design and analysis of hybrid PSO-GSA tuned PI and SMC controller for DC-DC Cuk converter," in IET Circuits, Devices \& Systems, vol. 13, no. 3, pp. 374-384, 2019.

[18] Moutabir Ahmed, Abdelmounim Elhassane, Aboulfatah Mohamed, "Modelling and Passivity-based Control of a Non Isolated DC-DC Converter in a Fuel Cell System," International Journal of Electrical and Computer Engineering (IJECE), vol. 8, no. 5, pp. 3436-3443, Oct. 2018.

[19] Eko Setiawan and Ichijo Hodaka, "A Novel Nonlinear Control of Boost Converter using CCM Phase Plane," International Journal of Electrical and Computer Engineering (IJECE), vol. 8, no. 6, pp. 4282-4289, Dec. 2018.

[20] Chakraborty, S., et al., "DC-DC Converter Topologies for Electric Vehicles, Plug-in Hybrid Electric Vehicles and Fast Charging Stations: State of the Art and Future Trends," Energies, vol. 12, no. 8, pp. 1-43, 2019.

[21] Korth Pereira Ferraz, P. and Kowal, J., "A Comparative Study on the Influence of DC/DC-Converter Induced High Frequency Current Ripple on Lithium-Ion Batteries," Sustainability, vol. 11, no. 21, pp. 1-17, 2019.

[22] Lee, I.-O., and Lee, J.-Y., "A High-Power DC-DC Converter Topology for Battery Charging Applications," Energies, vol. 10, no. 7, pp. 1-17, 2017.

[23] Fang Lin Luo and Hong Ye, "Negative Output Super-Lift Converters," In IEEE Transactions on Power Electronics, vol. 18, no. 5, pp. 1113-1121, Sep. 2003

[24] X. Jia, C. Hu, S. Du, M. Chen, P. Lin and D. Xu, "Dc-Link Voltage Control Strategy of a Bi-Directional DC/DC Converter for Electric Vehicles," 2015 IEEE Energy Conversion Congress and Exposition (ECCE), Montreal, Qc, pp. 92-99, 2015.

[25] K. Sharma and D. K. Palwalia, "Design of Digital PID Controller for Voltage Mode Control of Dc-Dc Converters," 2017 International Conference on Microelectronic Devices, Circuits, and Systems (ICMDCS), Vellore, India, pp. 1-6, 2017.

[26] T. A. Smith, S. Dimitrijev and H. B. Harrison, "Controlling A Dc-Dc Converter by Using the Power Mosfet as A Voltage Controlled Resistor," In IEEE Transactions on Circuits and Systems I: Fundamental Theory and Applications, vol. 47, no. 3, pp. 357-362, Mar. 2000.

[27] J. B. Robin and V. Chamundeeswari, "Modeling, Analysis, and Control of Inoslc (Improved Negative Output Super-Lift Luo Converter) Using Pi Controller," 2016 Second International Conference on Science Technology Engineering and Management (ICONSTEM), Chennai, India, pp. 475-480, 2016.

[28] Mallick, P.K., Balas, V.E., Bhoi, A.K., Zobaa, A.F., "Cognitive Informatics and Soft Computing," Proceeding of CISC 2017, Springer Nature Singapore Pte Ltd., 2020. https://doi.org/10.1007/978-981-15-1451-7. 